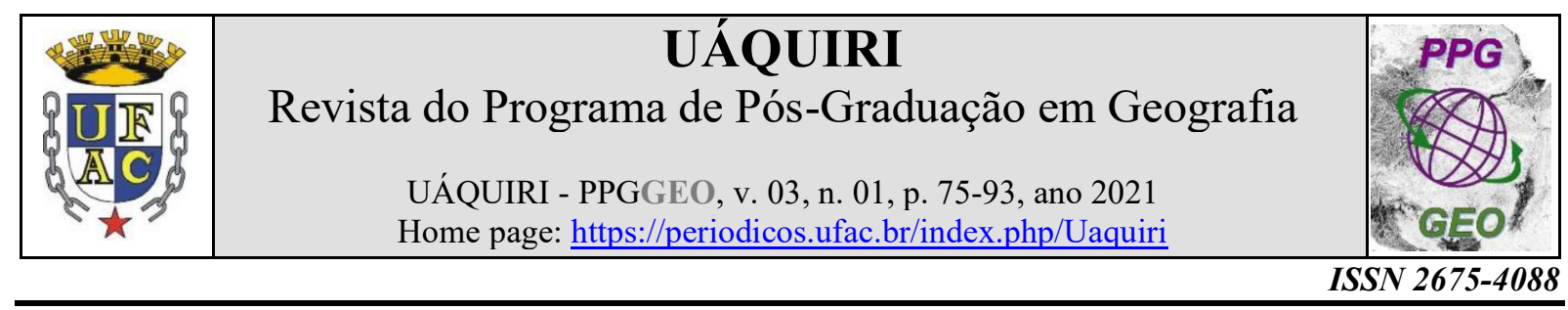

\title{
AS UNIDADES DE CONSERVAÇÃO AMBIENTAL DO NORTE DO ESTADO DO TOCANTINS E SUA IMPORTÂNCIA PARA A BIODIVERSIDADE DA REGIÃO
}

\author{
Saimon Lima de Britto ${ }^{1}$ \\ Orcid: https://orcid.org/0000-0001-5168-8747
}

${ }^{1}$ Doutorando em Geografia pela Universidade Federal de Goiás (IESA/UFG); Fiscal Ambiental do Instituto Natureza do Tocantins; Araguaína, Tocantins, Brasil.

*saimonlima@live.com

Recebido em: 24/03/2021; Aceito em: 18/06/2021; Publicado em: 30/07/2021

DOI: https://doi.org/10.47418/uaquiri.vol3.n1.2021.4697

\begin{abstract}
RESUMO
A presente pesquisa tem o objetivo de analisar a importância das unidades de conservação do norte do Estado de Tocantins para a proteção da biodiversidade local. Na pesquisa foi realizado um levantamento bibliográfico sobre o tema, a confecção de mapas para melhor retratar a pesquisa, além de trabalho de campo na região. Foi diagnosticado a presença de seis unidades de conservação na região norte do Estado do Tocantins, cada uma delas com sua importância específica para a região, tais como a preservação da fauna e da flora da área de transição dos biomas Cerrado e Amazônia, a presença indígena vinculada a preservação ambiental e as áreas de uso sustentável que unem preservação ambiental com ações antrópicas.
\end{abstract}

Palavras - chave: Unidades de Conservação; Estado do Tocantins; Biodiversidade; Bioma Cerrado; Bioma Amazônia.

\section{ENVIRONMENTAL CONSERVATION UNITS IN THE NORTH OF THE STATE OF TOCANTINS AND THEIR IMPORTANCE FOR THE BIODIVERSITY OF THE REGION}

\begin{abstract}
This research aims to analyze the importance of conservation units in the north of the State of Tocantins for the protection of local biodiversity. In the research, a bibliographic survey was carried out on the subject, the making of maps to better portray the research, in addition to fieldwork in the region. The presence of six conservation units in the northern region of the State of Tocantins was diagnosed, each one with its specific importance for the region, such as the preservation of fauna and flora in the transition area of the Cerrado and Amazon biomes, the indigenous presence linked to environmental preservation and sustainable use areas that combine environmental preservation with anthropic actions. Keywords: conservation units; Tocantins State; biodiversity; savanna biome; Amazon biome.
\end{abstract}

1 Doutorando em Geografia pela Universidade Federal de Goiás; Graduado e Mestre em Geografia pela Universidade Federal do Tocantins; Especialista em Educação em Direitos Humanos pela Universidade Federal do Tocantins. Membro do Núcleo de Estudos e Pesquisas em Geografia Agrária e Dinâmicas Territoriais (NEPAT/IESA/UFG); Membro do Núcleo de Estudos Urbanos Regionais e Agrários (NURBA/UFT); Fiscal Ambiental do Instituto Natureza do Tocantins - Naturatins. 


\section{LAS UNIDADES DE CONSERVACIÓN AMBIENTAL EN EL NORTE DEL ESTADO DE TOCANTINS Y SU IMPORTANCIA PARA LA BIODIVERSIDAD DE LA REGIÓN}

\section{RESUMEN}

Esta investigación tiene como objetivo analizar la importancia de las unidades de conservación en el norte del estado de Tocantins para la protección de la biodiversidad local. En la investigación se realizó un relevamiento bibliográfico sobre el tema, la elaboración de mapas para retratar mejor la investigación, además del trabajo de campo en la región. Se diagnosticó la presencia de seis unidades de conservación en la región norte del Estado de Tocantins, cada una con su importancia específica para la región, como la preservación de fauna y flora en el área de transición de los biomas del Cerrado y Amazonas, la presencia indígena vinculada a la preservación ambiental y áreas de uso sustentable que combinan la preservación ambiental con acciones antrópicas.

Palabras clave: Unidades de Conservación; Estado de Tocantins; biodiversidad; bioma de la sabana; Amazon Biome.

\section{1 - INTRODUÇÃO}

As práticas humanas estão cada vez mais destruindo os recursos naturais essenciais à vida na Terra, a produção capitalista, bem como o aumento populacional, pressiona o meio ambiente, que não consegue se recuperar na mesma velocidade em que é destruído / consumido. Gradualmente precisamos implementar práticas sustentáveis em nosso cotidiano, com vistas a manter a vida, mas não somente, mas também a vida com qualidade, e para isso precisamos respeitar e preservar o ciclo natural dos nossos biomas, fauna e flora.

Dessa forma a criação de Unidades de Conservação (UC) são ferramentas indispensáveis para essa preservação ambiental da biodiversidade e o uso sustentável consciente, porém essas áreas devem ser implantadas integralmente, ou seja, na lei e na prática, paralelo a educação ambiental com a população envolvida na criação dessas áreas para que assim possam participar desse processo entendendo sua importância. O Estado do Tocantins está localizado na região norte do Brasil, tem todo o seu território inserido na Amazônia Legal ${ }^{1}$ e no MATOPIBA ${ }^{2}$.

De acordo com Júnior, Coutinho e Freitas (2009, p. 25):

Ao longo dos anos 80 do século XX, a preocupação com a conservação da biodiversidade do planeta adquiri importância internacional diante das

\footnotetext{
${ }^{1}$ A Amazônia Legal é uma área que corresponde a 59\% do território brasileiro e engloba a totalidade de oito estados (Acre, Amapá, Amazonas, Mato Grosso, Pará, Rondônia, Roraima e Tocantins) e parte do Estado do Maranhã. O conceito de Amazônia Legal foi instituído em 1953 e seus limites territoriais decorrem da necessidade de planejar o desenvolvimento econômico da região. (Ipea, 2021).

2 O MATOPIBA é uma região formada por áreas majoritariamente de cerrado nos Estados do Maranhão, Tocantins, Piauí e Bahia, o nome é um acrônimo formado pelas siglas dos quatro estados (MA + TO + PI + BA). Se destaca pelo cultivo de grãos e fibras, especialmente soja, milho e algodão (Embrapa, 2021).
} 
emergências de suas situações: a comunidade científica começa a identificar novo processo de extinção de espécies com taxas muito elevadas, particularmente nos trópicos, e a ciência descobre novos usos e aplicações para a biodiversidade biológica, como matéria-prima para modernas biotecnologias em atividades econômicas. (JÚNIOR, et al, 2008, p. 25).

Dois pontos chave são identificados na fala dos autores, onde se diz que "novo processo de extinção de espécies com taxas muito elevadas", ou seja, uma ameaça veemente de extinção da vida humana na terra através dos desequilíbrios biológicos do sistema e, "a ciência descobre novos usos e aplicações para a biodiversidade biológica, como matéria-prima para modernas biotecnologias em atividades econômicas" deixando claro a importância econômica para a comunidade mundial na fabricação de fármacos, cura e tratamento para doenças, cosméticos, entre outros.

Segundo Associação O Eco (2014), a diversidade biológica ou biodiversidade é o grau de variação da vida. Definida em termos de genes, espécies e ecossistemas. No seu uso comum, o termo é usado para descrever o número e a variedade dos organismos vivos. Ou seja, a importância da biodiversidade vai além das possibilidades econômicas, mas em especial para a preservação da vida na Terra como a conhecemos. Para Wilson (P.1, 1997) a biodiversidade se define:

\begin{abstract}
Biodiversidade é toda variação em todos os níveis de organização, desde os genes dentro de uma simples população local ou espécie, até as espécies que compõem parte de uma comunidade local e, finalmente, as próprias comunidades que compõem a parte viva dos ecossistemas multifatoriais do mundo. A chave precisa para a efetiva análise da biodiversidade está em cada nível de organização que está sendo discutido (WILSON, p.1, 1997. Apud. OLIVEIRA; MARANDINO).
\end{abstract}

Região de transição do bioma Cerrado para o bioma Amazônia, a região trata-se de grande variedade de espécies endêmicas, rica em biodiversidade. A pesquisa se faz importante pelas particularidades locais e regionais, essas por sua vez incluem aldeias indígenas, pequenas cidades, espécies endêmicas, e ao mesmo tempo uma região totalmente incluída na última fronteira agrícola, o MATOPIBA, recebendo grande pressão do agronegócio moderno e globalizado. Propõe - se através do reconhecimento e caracterização dessas áreas uma maior conservação e preservação ambiental, através das Unidades de Conservação (UC), dessas áreas abundantes em biodiversidade.

Este trabalho tem por objetivo fazer uma análise da importância das Unidades de Conservação (UC) para a biodiversidade da região norte do Estado do Tocantins. Foi realizado a especificação de cada UC presente na região norte do Estado do Tocantins levando em 
consideração que se trata de uma área de transição entre os biomas Cerrado e Amazônia, e por fim comentar sobre a presença indígena na região e suas relações com essas áreas protegidas por lei para preservação da fauna e da flora.

\section{2 - FUNDAMENTAÇÃO TEÓRICA E METODOLÓGICA}

\section{1 - Aspectos Teóricos}

As Unidades de Conservação (UC) se constituem em um meio mais que importante para a preservação da natureza. Através delas ações antrópicas são evitadas, pois, são áreas protegidas por leis e fiscalizadas pelos órgãos ambientais municipais, estaduais e federais, cada um dentro da sua jurisdição. Dentro delas o controle é rígido, pois dependendo da classificação nenhuma atividade pode ser desenvolvida dentro dessas áreas. Sobre as Unidades de Conservação, de acordo com Garbalini (2011, p.7):

\footnotetext{
As Unidades de Conservação constituem o meio para o estudo e preservação da fauna e flora nativas de um bioma e caracteriza-se como importante instituto na proteção ambiental e compatibilização do uso dos recursos naturais com o desenvolvimento econômico, social e turístico de uma região. (GARBALINI, 2011, P.7)
}

Garbalini esclarece de forma clara e sucinta a importância das Unidades de Conservação e sua função social voltada para os estudos e preservação da fauna e da flora, bem como a compatibilização do uso dos recursos naturais, em alguns casos. Sobre a criação e implantação das Unidades de Conservação, ainda de acordo com Garbelini (2011):

O desafio está na efetiva implementação destas unidades de conservação, as quais são criadas por atos do poder público, mas, corriqueiramente, não são concretizadas as medidas necessárias para a sua regular existência, como a elaboração do plano de manejo, a constituição do conselho e a regularização fundiária, quando for o caso. (GARBELINI, 2011, p. 5).

A autora ressalta a "efetiva implantação" das unidades de conservação, uma vez que são implantadas mediante leis, decretos e normas, porém, na prática, faltam investimentos do poder público em efetivar essas unidades de conservação com a elaboração e aplicação do plano de manejo, a instituição e atuação dos conselhos ambientais, municipais, estaduais e federais e as regularizações fundiárias existentes na maioria desses procedimentos. Outro ponto relevante para a implantação efetiva dessas áreas é o fortalecimento dos órgão ambientais fiscalizadores. Ainda sobre a implantação de Unidades de Conservação Baptista e Oliveira (2002) afirmam que: 
A instituição de Unidades de Conservação se dá por ato do poder público, devendo ser realizados estudos técnicos prévios para que se determinem sua localização, sua dimensão e seus limites. É interessante notar que uma vez instituída uma Unidade de Conservação, mesmo através de um decreto ou de uma norma inferior, sua extinção ou redução somente pode ser feita através de lei específica. (BAPTISTA; OLIVEIRA, 2002, p.20).

Vemos que após sua instituição por ato do poder público, as Unidades de Conservação só podem ser extintas mediante aprovação de lei, ou seja, deve passar novamente pelo poder legislativo, o que torna a criação mais fácil do que sua extinção. Essa ferramenta jurídica se dá justamente para evitar que Unidades de Conservação já criadas sejam extintas em prol de interesses particulares que por ventura se dão com as mudanças de governos.

De acordo com Chiavenato (1991, p.10) em seu livro, O Massacre da Natureza, diz que "A Terra é frágil. Melhor, ficou frágil.", o autor se refere ao uso exaustivo que o ser humano faz do nosso planeta Terra, pois afirma que não "é" "ficou", devido a intensidade dos usos dos recursos naturais que não permitem que a natureza se recomponha em tempo hábil para estar disponível novamente para a humanidade. Para Castro Junior (et al, 2009):

Pensando além das razões ambientais, socioeconômicas e políticas relacionadas a conservação ambiental, a complexidade que enreda a materialidade da biodiversidade cria desafios conceitual-teóricos no debate sobre a conservação do meio ambiente e seu uso sustentável pelo sistema capitalista de produção (CASTRO JR. ET AL. 2009).

O autor pontua um equilíbrio difícil de ser colocado em prática, a conservação do meio ambiente com o uso sustentável pelo sistema capitalista de produção. Isso porque sabemos que o sistema capitalista visa unicamente o lucro, a produção do mais valor para a acumulação do capital e isso significa custos baixos de produção o que dificilmente irá estar alinhado com o uso sustentável dos recursos naturais.

Em 18 de julho de 2000, foi instituída a Lei Federal $\mathrm{n}^{\circ} 9.985$ que Regulamenta o art. 225, § 1ำ, incisos I, II, III e VII da Constituição Federal e institui o Sistema Nacional de Unidades de Conservação da Natureza - SNUC. Esse sistema estabelece critérios e normas para a criação, implantação e gestão das unidades de conservação no país. De acordo com o Ministério do Meio Ambiente - MMA.

O Sistema Nacional de Unidades de Conservação - SNUC - é o conjunto de unidades de conservação (UC) federais, estaduais e municipais. É composto por 12 categorias de UC, cujos objetivos específicos se diferenciam quanto à forma de proteção e usos permitidos: aquelas que precisam de maiores cuidados, pela sua fragilidade e particularidades, e aquelas que podem ser utilizadas de forma sustentável e conservadas ao mesmo tempo. (BRASIL, 2018). 
Segundo o Ministério do Meio Ambiente, na categorização do SNUC, são 12 os tipos de Unidades de Conservação, e são divididos em dois grupos as "Unidades de Proteção Integral" e as "Unidades de Uso Sustentável". Essa categorização se dá para melhor gestão e controle de uso e proteção dessas áreas, na tentativa de mitigar ao máximo os impactos ambientais causados pela ação humana. Segue quadro $1 \mathrm{com}$ as divisões por grupos de UC.

Quadro 1.: Tipos de Unidades de Conservação

\begin{tabular}{|c|c|}
\hline \multicolumn{2}{|c|}{ UNIDADES DE CONSERVAÇÃo } \\
\hline Unidades de Proteção Integral & Unidades de Uso Sustentável \\
\hline Estação Ecológica & Área de Proteção Ambiental \\
\hline Reserva Biológica & Área de Relevante Interesse Ecológico \\
\hline Parque Nacional & Floresta Nacional \\
\hline Monumento Natural & Reserva Extrativista \\
\hline Refúgio da Vida Silvestre & Reserva de Desenvolvimento Sustentável \\
\hline & Reserva Particular do Patrimônio Natural \\
\hline
\end{tabular}

Fonte: Mistério do Meio Ambiente (2018). Org. Saimon Lima de Britto, (2018).

De acordo com o MMA (2018), as Unidades de Proteção Integral têm como principal objetivo a proteção da natureza, por isso as regras e normas são mais restritivas. Nesse grupo é permitido apenas o uso indireto dos recursos naturais; ou seja, aquele que não envolve consumo, coleta ou danos aos recursos naturais. Exemplos de atividades de uso indireto dos recursos naturais são: recreação em contato com a natureza, turismo ecológico, pesquisa científica, aulas campo, educação ambiental, entre outras.

Já as Unidades de Uso Sustentável, ainda de acordo com o MMA (2018), são áreas que visam conciliar a conservação da natureza com o uso sustentável dos recursos naturais. Nesse grupo, atividades que envolvem coleta e uso dos recursos naturais são permitidas, mas desde que praticadas de uma forma que a perenidade dos recursos ambientais renováveis e dos processos ecológicos esteja assegurada. Atividades nessas áreas requerem licenciamento ambiental ou anuência dos órgãos ambientais competentes. 


\section{2 - Aspectos Metodológicos}

Foi realizada uma pesquisa bibliográfica sobre o tema, que serviu para embasar e conduzir a pesquisa. De acordo com Leite (2008, p.47) “A pesquisa bibliográfica é fundamental, pois, além de ser autônoma, isto é, independente das outras, serve de base, de alicerce para o fundamento e alcance dos objetivos dos outros tipos de pesquisa.". Foram realizadas catalogação de obras literárias, bem como leis, decretos e normas que tratam da temática.

Também foram realizadas análises e confecções de mapas da região norte do Estado do Tocantins referente aos biomas em questão e a identificação e localização das referidas Unidades de Conservação. Para complementar a pesquisa foi usada informações de sites de órgãos oficiais do governo do Estado do Tocantins e do Governo Federal, além de trabalhos de campo na região para análise visual da paisagem e registros fotográficos. No mais foi realizado um levantamento dos tipos e conceitos de Unidades de Conservação presentes na região ressaltando suas importâncias socioambientais como um todo.

\section{3 - RESULTADOS E DISCUSSÃO}

\section{1 - Caracterizações da área de estudo}

É importante detalhar cada tipo de Unidade de Conservação presente na região norte do Estado do Tocantins. Dos 12 tipos de UC's existentes no Brasil, a região norte do Estado do Tocantins possuí quatro tipos de Unidades de Conservação de Uso Sustentável, são três Áreas de Proteção Ambiental (APA), e uma Reserva Extrativista (RESEX) e uma UC de Proteção Integral, o Monumento Natural. A referida região também contém duas Reservas Indígenas, que não constam na lista de Unidades de Conservação, possuí legislação própria, porém é de grande importância para a preservação da biodiversidade. Para melhor entendimento a seguir vamos compreender qual o papel de cada uma dessas áreas.

Para entendermos o quão importante são essas áreas de preservação da natureza, não podemos deixar de explanar sobre os biomas presentes na referida região. O Estado do Tocantins está localizado na região Norte do Brasil e tem seu território coberto por $91 \%$ de bioma Cerrado e 9\% de bioma Amazônia. Por se tratar de zona de transição entre os dois biomas, a região também é rica em espécies endêmicas, tanto da fauna como da flora. Segue Figura 1 do Mapa dos Biomas presentes no Estado do Tocantins. 
Figura 1: Mapa dos Biomas Presentes no Estado do Tocantins

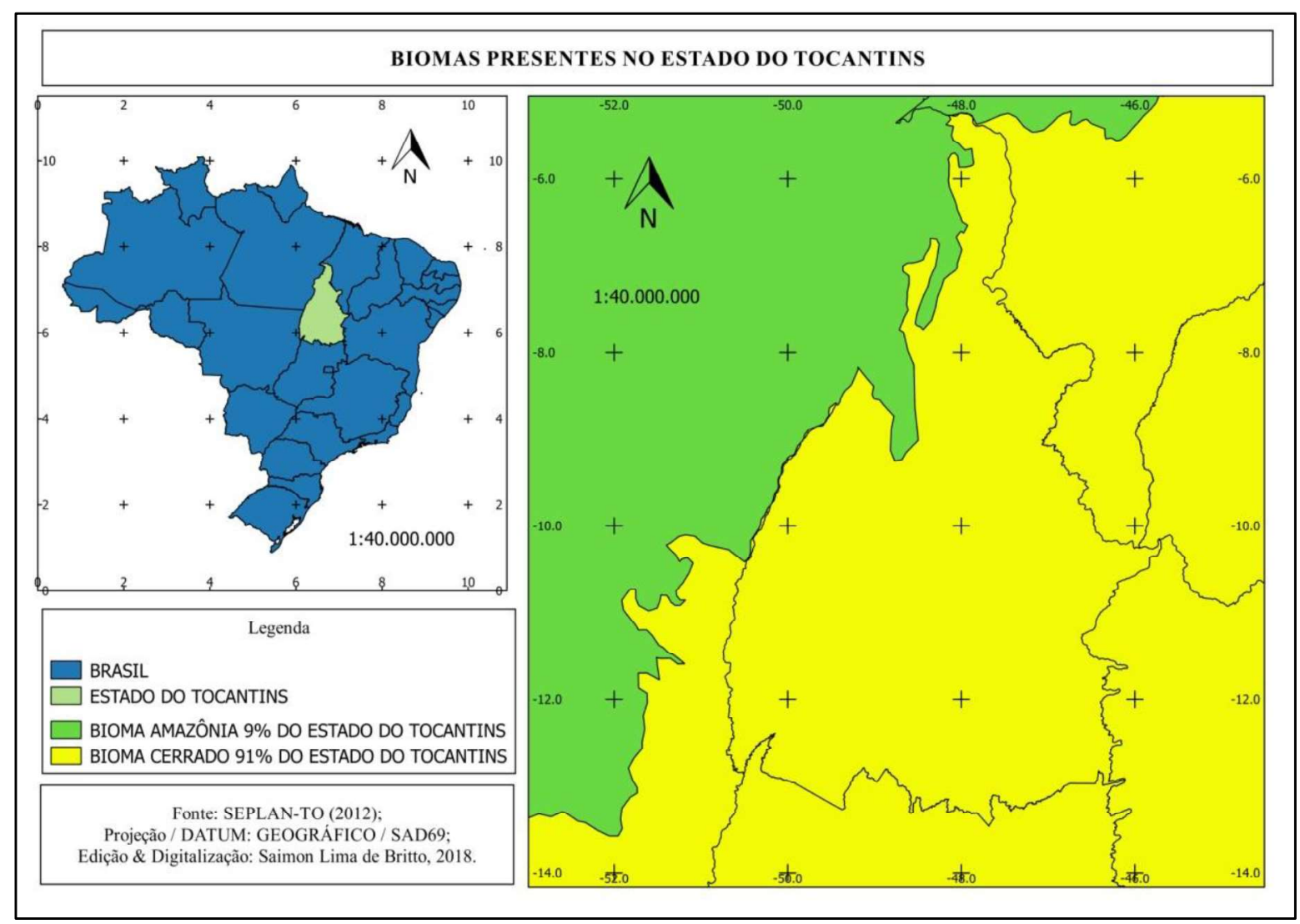

Fonte: Seplan-TO (2012). Org. Saimon Lima de Britto (2018).

A forte presença do bioma Cerrado e a parcela de bioma Amazônia fazem com que haja a necessidade de criação de Unidades de Conservação, ora pelo Estado, ora pelos Municípios, ou pelo Governo Federal no intuito de preservar a biodiversidade garantindo a qualidade e a manutenção da vida. A região norte do Estado do Tocantins comporta a transição entre os biomas e merece toda nossa atenção em relação às Unidades de Conservação presentes nessa área.

\subsubsection{O Bioma Amazônia}

O bioma Amazônia é o maior bioma do Brasil, com território de 4,196.943 (quatro milhões, cento e noventa e seis mil, novecentos e quarenta e três) km2, crescem 2.500 espécies de árvores e 30 mil espécies de plantas das 100 mil da América do Sul (BRASIL, 2018). Do território tocantinense 9\% são de bioma Amazônia. De acordo com o Ministério do Meio Ambiente - MMA (2018), a bacia amazônica é a maior bacia hidrográfica do mundo, cobre cerca de 6 milhões de $\mathrm{km}^{2}$ e têm 1.100 afluentes. Seu principal rio, o Amazonas, corta a região 
para desaguar no Oceano Atlântico, lançando ao mar cerca de 175 milhões de litros d'água a cada segundo.

Seus recursos naturais incluem enormes estoques de madeira, borracha, castanha, peixe e minérios, por exemplo, e representam uma abundante fonte de riqueza natural. A região abriga também grande riqueza cultural, principalmente provindos das comunidades tradicionais, como é o caso dos indígenas, incluindo o conhecimento tradicional sobre os usos e a forma de explorar esses recursos naturais sem esgotá-los nem destruir o habitat natural.

O ecossistema local é frágil, a floresta vive a partir de seu próprio material orgânico, e seu delicado equilíbrio é extremamente sensível a quaisquer interferências. Os danos causados pela ação antrópica são muitas vezes irreversíveis. A demais, a riqueza natural da Amazônia se contrapõe dramaticamente aos baixos índices socioeconômicos, de baixa densidade demográfica e crescente urbanização. Desta forma, o uso dos recursos florestais é estratégico para o "desenvolvimento" da região.

\subsubsection{O Bioma Cerrado}

Segundo o Ministério do Meio Ambiente (2018), o Cerrado é o segundo maior bioma da América do Sul, ocupando uma área de 2.036.448 (dois milhões, trinta e seis mil, quatrocentos e quarenta e oito) $\mathrm{km}^{2}$, cerca de $22 \%$ do território nacional. A sua área contínua incide sobre 15 Estados, entre eles o Estado do Tocantins com 91\% de seu território coberto pelo bioma cerrado. Neste espaço territorial encontram-se as nascentes das três maiores bacias hidrográficas da América do Sul, Amazônica/Tocantins, São Francisco e Prata, o que resulta em um elevado potencial aquífero e favorece a sua biodiversidade.

O MMA (2018) afirma que do ponto de vista da diversidade biológica, o cerrado brasileiro é reconhecido como a savana mais rica do mundo, abrigando 11.627 (onze mil seiscentos e vinte e sete) espécies de plantas nativas já catalogadas. O Cerrado apresenta extrema abundância de espécies endêmicas, que sofre uma excepcional perda de seu habitat através das grandes lavouras, especialmente de soja e silviculturas de eucalipto. Essa situação se agravou com a implantação do território do MATOPIBA, onde o bioma cerrado se vê ameaçado com o avanço das grandes produções de grãos.

Ainda de acordo com os dados oficiais do MMA (2018), são elevados os números de espécies no Cerrado, 199 espécies de mamíferos são conhecidas, a avifauna compreende cerca de 837 espécies, cerca de 1200 espécies de peixes, 180 espécies de répteis e 150 espécies de anfíbios. O número de peixes endêmicos não é conhecido, porém os valores são bastante altos 
para anfíbios e répteis, $28 \%$ e $17 \%$, respectivamente. De acordo com estimativas recentes, o Cerrado é o refúgio de $13 \%$ das borboletas, $35 \%$ das abelhas e $23 \%$ dos cupins dos trópicos.

Além dos aspectos ambientais, o Cerrado tem grande importância social. Muitas populações sobrevivem de seus recursos naturais, incluindo indígenas, quilombolas, geraizeiros, ribeirinhos, babaçueiras, vazanteiros, camponeses, entre outros, que juntas fazem parte do patrimônio histórico e cultural brasileiro e tocantinense, e que detêm um conhecimento tradicional de sua biodiversidade. Esse conhecimento empírico vai passando de geração a geração, porém, também está ameaçado juntamente com extinção dos povos e comunidades tradicionais.

\section{2 - Terras Indígenas na Região Norte do Estado do Tocantins}

A região norte do Estado do Tocantins possui duas Terras Indígenas, que não são Unidades de Conservação, pois possui sua legislação própria através da Constituição Federal de 1988, da Lei Federal nº 6001 de 1973 (Estatuto do Índio) e do Decreto Federal n ${ }^{\circ} 1775$ de 1996, porém, as Terras Indígenas acabam funcionando como uma UC, vez que sua instituição e demarcação para uso exclusivo dos indígenas acabam por proteger a fauna, a flora e os recursos hídricos, essenciais para a manutenção da cultura e sobrevivência dos indígenas.

De acordo com a Secretaria de Planejamento do Estado do Tocantins - Seplan-TO (2012) as Terras Indígenas são áreas tradicionalmente ocupadas pelos índios, as por eles habitadas em caráter permanente, as utilizadas para suas atividades produtivas, as imprescindíveis à preservação dos recursos ambientais necessários a seu bem-estar e as necessárias a sua reprodução física e cultural, segundo seus usos, costumes e tradições.

Ainda de acordo com a Seplan-TO (2012) as Terras Indígenas presentes no norte do Estado do Tocantins são, a Terra Indígena Apinajé ocupada tradicionalmente pela etnia Apinajé e a Terra Indígena Xambioá ocupada tradicionalmente pelas etnias Guaraní e Karajá. O Decreto Federal s/n de 03 de Novembro de 1997 homologa a demarcação administrativa das Terras Indígenas Apinajé e Xambioá. Segue figura 2 com o mapa de localização das Terras Indígenas da região norte do Estado do Tocantins. 
Figura 2: Mapa de localização das Terras Indígenas da região norte do Estado do Tocantins

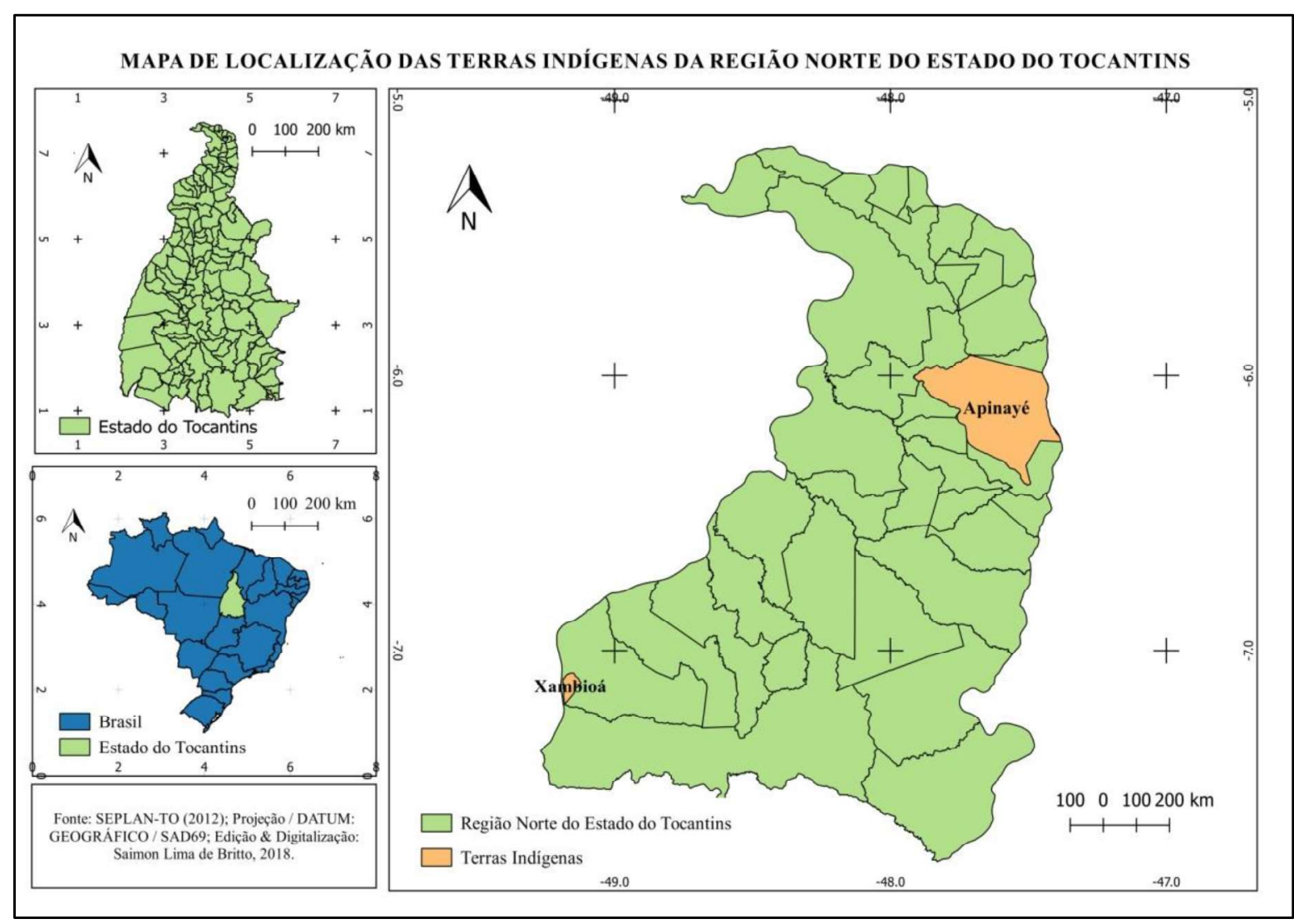

Fonte: Seplan - TO (2012). Org. Saimon Lima de Britto (2018).

De acordo com informações da Fundação Nacional do Índio - FUNAI (2018) a Terra Indígena Apinajé possui 141.904,2092 hectares de área demarcada e se localiza em cinco municípios tocantinenses, são eles, Itaguatins, Maurilândia do Tocantins, Cachoeirinha, São Bento do Tocantins e Tocantinópolis, já a Terra Indígena Xambioá possui uma área de 3.326,3502 hectares e se localiza no Município de Santa Fé do Araguaia - TO.

\subsection{Unidades de Conservação no Norte do Estado do Tocantins}

De acordo com Coelho, et al. (2009, p. 78) “As unidades de conservação são criadas por força de lei e consolidadas por práticas e instituições regulatórias criadas e mantidas por indivíduos ou grupos sociais, acordadas e legitimadas pelo Poder Público" é importante observar que a proteção de áreas sejam públicas ou privadas se dá sempre com aval do poder público e suas agências e instituições fiscalizadoras e reguladoras.

Muitos são os desafios tanto para implantação, como para a preservação dessas áreas, pois são diversos os conflitos sociais presentes nesses processos, uma vez que envolvem interesses públicos e privados de donos de terras, produtores rurais, prefeituras, comunidades 
tradicionais, entre outros. Geralmente, proprietários de terras que possuem em suas propriedades uma UC, se sentem prejudicados por não poderem usar sua terra de forma integral, uma vez que ao ser reconhecida como uma Unidade de Conservação a área passa a ser tutelada pelo estado e nada pode ser feito sem o consentimento justificado deste.

Em 5 de abril de 2005 o Governo do Estado do Tocantins institui o Sistema Estadual de Unidades de Conservação da Natureza - SEUC e estabelece critérios e normas para a criação, implantação e gestão das unidades que o constituem. O SEUC é um sistema que faz a gestão das Unidades de Conservação no âmbito Estadual contribuindo para a manutenção da diversidade biológica, a proteção das espécies endêmicas e contribuindo para a preservação e a restauração da diversidade dos ecossistemas.

O SEUC é composto pelo Conselho Estadual de Meio Ambiente-COEMA, a Secretaria do Planejamento e Meio Ambiente - SEPLAN, o Instituto Natureza do Tocantins NATURATINS e os órgãos Municipais Ambientais. Segue figura 3 do Mapa de localização das Unidades de Conservação na região norte do Estado do Tocantins.

Figura 3: Mapa de localização das Unidades de Conservação na região norte do Estado do Tocantins.

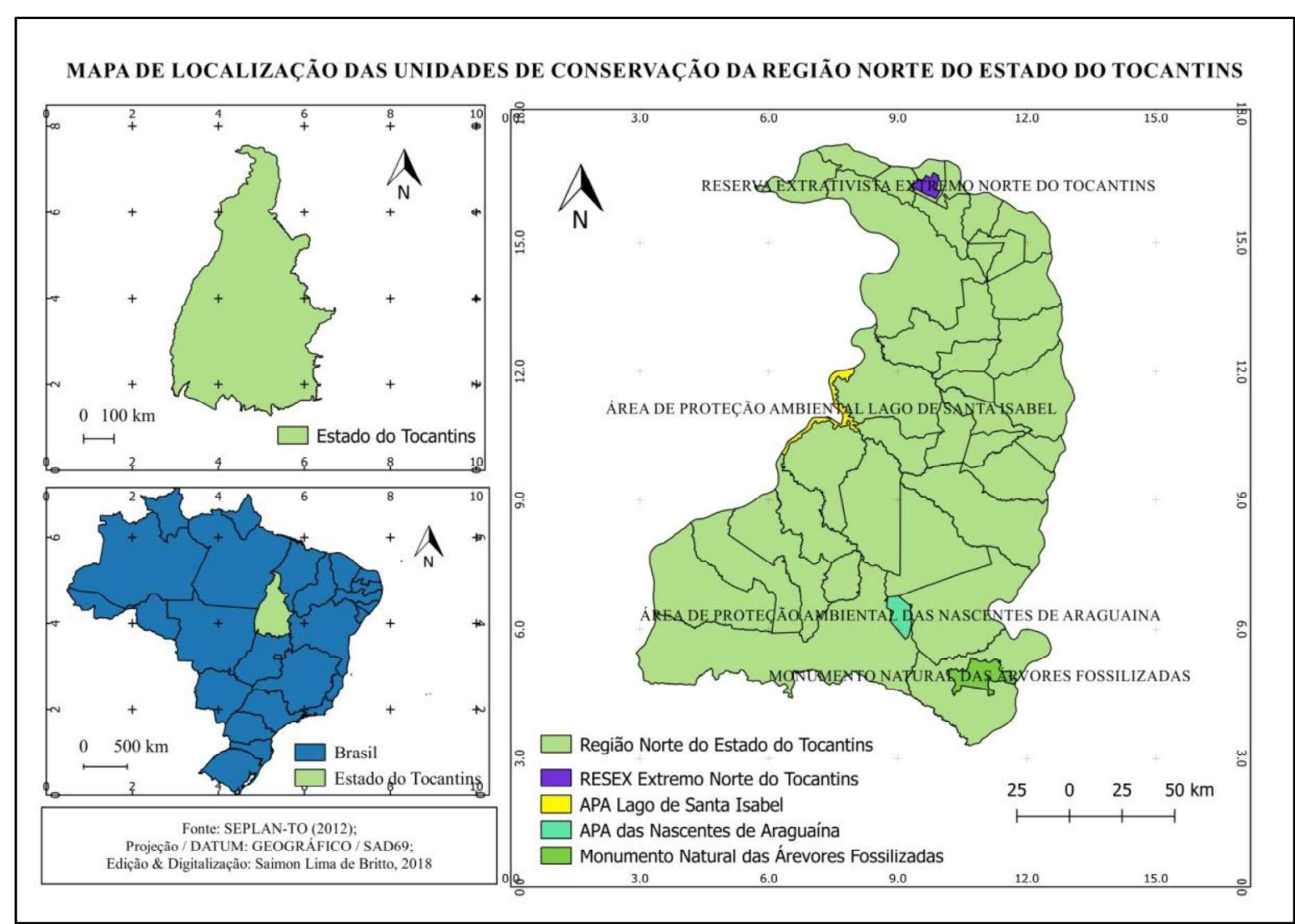

Fonte: IBGE (2018). Org. Saimon Lima de Britto (2018). 
Atualmente a região Norte do Estado do Tocantins possui 6 Unidades de Conservação, algumas já implantadas, outras apenas demarcadas e fixadas em Lei. São elas, a saber: a Área de Proteção Ambiental das Nascentes de Araguaína; a Área de Proteção Ambiental Lago de Santa Isabel; o Monumento Natural das Árvores Fossilizadas do Tocantins; a Reserva Extrativista Extremo Norte do Estado do Tocantins; a Área de Proteção Ambiental Sapucaia; a Área de Proteção Ambiental do Rio Taquari. Essas duas últimas não constam no mapa por falta de dados geográficos nos órgãos oficiais IBGE e Seplan-TO. O SEUC tem o papel importante na gestão dessas áreas, inclusive na inter-relação com as comunidades locais. A seguir especificaremos cada uma das Unidades de Conservação presentes na referida região com base nas informações técnicas dos órgãos oficiais.

De acordo com o Ministério do Meio Ambiente (2018), a Área de Proteção Ambiental (APA) é de Uso Sustentável, área dotada de atributos naturais, estéticos e culturais importantes para a qualidade de vida e o bem-estar das populações humanas. Geralmente, é uma área extensa, com o objetivo de proteger a diversidade biológica, ordenar o processo de ocupação humana e assegurar a sustentabilidade do uso dos recursos naturais. É constituída por terras públicas e privadas. Nessas áreas é permitido o uso sustentável, através de licenciamentos ambientais dos órgãos competentes, quando couber. A seguir listaremos as APA's presentes na região norte do Estado do Tocantins e detalharemos cada uma delas.

A Área de Proteção Ambiental das Nascentes de Araguaína foi criada pelo Governo do Estado do Tocantins em 09 de dezembro de 1999, através da Lei Estadual n 1.116, localizase em sua maior parte no município de Araguaína. Contém uma área de 15.821,50,00 ha, localizada nos municípios de Araguaína, Babaçulândia e Wanderlândia. Ocupa uma área de remanescentes de floresta amazônica (1,53\%), com um cerrado mais denso, típico da região de transição dos biomas, com $(98,47 \%)$ de cerrado.

A APA das Nascentes de Araguaína, como o próprio nome já diz, tem por finalidade proteger as nascentes, os cursos d'água, a flora e os recursos naturais com potencial turístico, de forma a garantir o seu aproveitamento equilibrado, sustentável e compatível com a conservação de ecossistemas locais. Esta APA apresenta um elevado grau de antropização e nesse sentido o Conselho Gestor da APA contribui na proposição de programas de recuperação de nascentes e matas de galeria profundamente alteradas, bem como outros programas de educação ambiental e projetos voltados para a produção sustentável. 
A Área de Proteção Ambiental Sapucaia fica localizada no município de Piraquê TO e contém uma área de 17.208,80 hectares, foi criada pela Lei Municipal de $\mathrm{n}^{\circ} 104$ de agosto de 2004.

A Área de Proteção Ambiental Lago de Santa Isabel foi criada pelo governo do Estado do Tocantins através do Decreto $\mathrm{n}^{0} 1.558$ de agosto de 2002 e tem uma área de 18.608,1500 hectares, localiza-se nos municípios de Ananás, Riachinho, Xambioá e Araguanã. Foi criada com a finalidade de proteger e conservar as diversidades biológicas e disciplinar o processo de ocupação das áreas de entorno do reservatório a ser formado pela futura usina hidrelétrica de Santa Isabel.

A Área de Proteção Ambiental do Rio Taquari fica localizada no município de Araguatins-TO e foi criada pela Lei Municipal de $n^{\circ} 806$ de dezembro de 2002. A APA do Rio Taquari contém uma área total de 26.152 hectares (vinte e seis mil, cento e cinqüenta e dois hectares), e fica na microbacia do Rio Taquari. De acordo com a referida Lei, em seu inciso $1^{\circ}$ a APA tem por objetivo "proteger a qualidade das águas e as vazões do manancial que abastece a cidade de Araguatins, assegurando as condições de sobrevivência necessárias para a população humana".

A Unidades de Proteção Integral presente no norte do Tocantins é o Monumento Natural, detentor de patrimônio natural ímpar, singular ou raro, que de acordo com o Ministério do Meio Ambiente (2018):

É área destinada à preservação de lugares singulares, raros e de grande beleza cênica, permitindo diversas atividades de visitação. Essa categoria de UC pode ser constituída de áreas particulares, desde que as atividades realizadas nessas áreas sejam compatíveis com os objetivos da UC. (BRASIL, 2018).

O Monumento Natural das Árvores Fossilizadas do Tocantins - MONAF é uma Unidade de Conservação de Proteção Integral, instituída pelo Estado do Tocantins através de Lei Estadual de n ${ }^{0} 1.179$ de 04 de outubro de 2000. O MONAF é gerido pelo Instituto Natureza do Tocantins - Naturatins e conta com o trabalho técnico de Inspetores, Historiadores, Biólogos, Geógrafos, Guarda-Parques e Fiscais Ambientais do órgão.

A sede administrativa do MONAF está situada em Bielândia, distrito do município de Filadélfia, e abrange uma área de 32.067,1000 hectares de cerrado. Sua Zona de Amortecimento engloba parte do município de Babaçulândia, a aproximadamente $30 \mathrm{~km}$ de distância de Bielândia. De acordo com o Gesto-TO (2018) há alguns milhões de anos o Tocantins abrigou 
uma floresta que hoje é considerado um dos maiores registros de vegetais fossilizados do mundo. Segue figura 4, fotos do sítio paleontológico do Monumento Natural das Árvores Fossilizadas do Tocantins.

Figura 4: fotos do sítio paleontológico do Monumento Natural das Árvores Fossilizadas do Tocantins
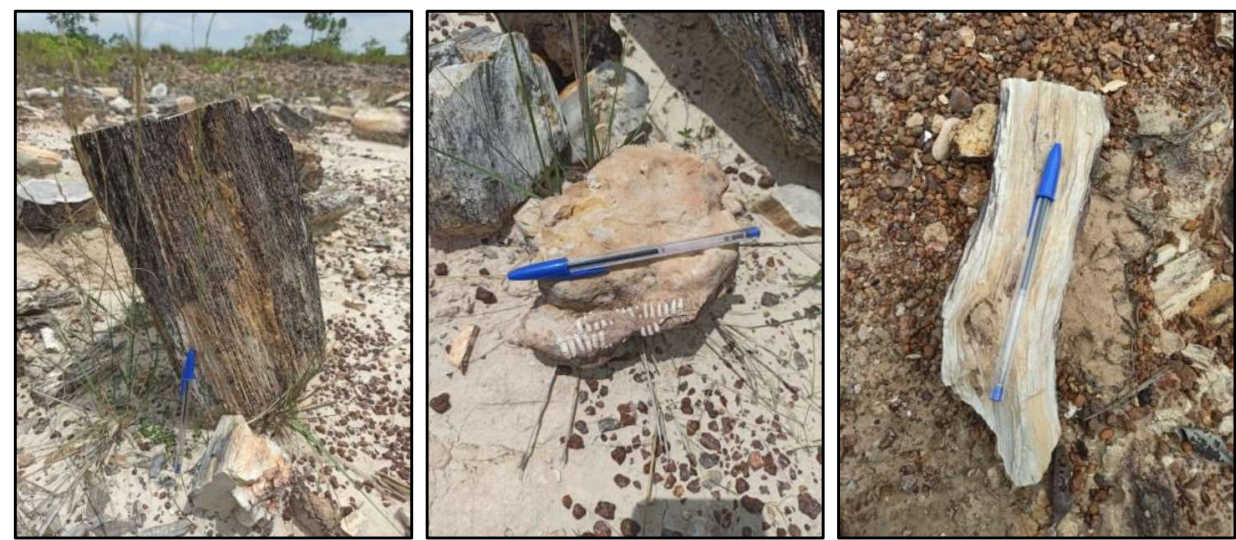

Fonte: Saimon Lima de Britto. Trabalho de campo (2020).

A existência de tais sítios paleontológicos e arqueológicos onde são encontrados os fósseis de árvores tais como pteridófitas, esfenófitas, coníferas e cicadácias, é laboratório a céu aberto para escolas e universidades do Brasil e do mundo, o monumento recebe regularmente grupos de pesquisadores de diferentes lugares, em especial dos cursos de biologia e geografia da Universidade Federal do Tocantins, que tem o MONAF como parte de sua agenda de aulas de campo, contribuindo assim para o estudo e o desenvolvimento da humanidade (GESTO, 2018).

Também presente na região norte do Estado do Tocantins está a Unidade de Conservação de uso Sustentável, se trata da Reserva Extrativista (RESEX), que segundo o Ministério do Meio Ambiente (2018):

É uma área natural utilizada por populações extrativistas tradicionais onde exercem suas atividades baseadas no extrativismo, na agricultura de subsistência e na criação de animais de pequeno porte, assegurando o uso sustentável dos recursos naturais existentes e a proteção dos meios de vida e da cultura dessas populações. Permite visitação pública e pesquisa científica. (BRASIL, 2018).

A Reserva Extrativista Extremo Norte do Estado do Tocantins, a única Unidade de Conservação Federal do norte do Estado, foi criada pelo Decreto Federal n ${ }^{\circ}$ 535, de 20 de maio 
de 1992, pelo então Presidente Fernando Collor de Melo. A Reserva fica localizada nos municípios de Carrasco Bonito-TO e Sampaio-TO. Possui uma área total de aproximadamente 9.124,98 hectares de babaçuais com o objetivo de assegurar a extração de coco babaçu pelas quebradeiras de coco e pelas demais comunidades tradicionais. A Reserva é de responsabilidade do IBAMA.

Sobre o babaçu é importante ressaltar que o Estado do Tocantins, em 2008, instituiu a Lei n 1.959 de 14 de agosto, popularmente conhecida por "Lei do Babaçu", que dispõe sobre a proibição da queima, derrubada e do uso predatório das palmeiras do coco babaçu e adota outras providências. O intuito é preservar a palmeira nativa e garantir a extração do coco pelas comunidades tradicionais do Estado. O Naturatins é o órgão estadual responsável pela fiscalização do cumprimento desta Lei.

\section{ALGUMAS CONSIDERAÇÕES}

É de consenso nas bibliografias que a porção norte do Estado do Tocantins é de relevante importância para a preservação da biodiversidade bem como a manutenção das comunidades tradicionais. É na porção Norte / Oeste do Estado do Tocantins que se encontra os 9\% de bioma Amazônia e a Norte / Leste um grande faixa de área de transição dos biomas Cerrado e Amazônia.

A região norte do Estado do Tocantins é muito rica em biodiversidade, possui 2 Terras Indígenas demarcadas e regularizadas pelo Governo Federal, que garantem a preservação da biodiversidade e das comunidades tradicionais que nelas ocupam. Além dessas a região possui 1 Unidade de Conservação Federal, 3 Estaduais e 2 Municipais. Nelas habitam camponeses, ribeirinhos, quilombolas, extrativistas, quebradeiras de coco, indígenas, entre outros.

As Unidades de Conservação são de extrema importância não somente para a sociedade local, mas para toda a humanidade. Elas garantem a preservação dos cursos hídricos, da fauna e da flora. Além disso, essas áreas garantem também o modo de vida cultural das comunidades tradicionais locais, seus conhecimentos empíricos que são repassados dos pais para os filhos e filhas. As Unidades de Conservação preservam também o clima local e regional, como o período das chuvas e a umidade do ar, que está totalmente ligado a saúde pública.

O que se percebeu foi que as Unidades são criadas em Leis, porém falta um plano de manejo para estabelecer as normas e restrições para o uso dessas áreas, também falta uma educação ambiental com a sociedade local no intuito de esclarecer do que se trata e seus benefícios. Outro ponto que causa grande problema na implantação e gestão dessas áreas são 
as indenizações por parte do Estado à sociedade impactada diretamente, essas indenizações geralmente demoram a acontecer e nem sempre as pessoas impactadas se sentem satisfeitas com o resultado. As unidades de conservação precisam de não apenas de uma legislação que as resguarde, é preciso também a participação massiva e consciente da sociedade que as cercam, bem como o fortalecimento dos órgãos fiscalizadores.

\section{REFERÊNCIAS}

ARAGUATINS. Lei Municipal no 806 de 20 de dezembro de 2002. Cria a Área de Proteção Ambiental - APA do Rio Taquari, e dá outras providências. Disponível em: http://www.araguatins.to.leg.br/leis/leis-sancionadas/2002/lei-no-806-de-20-12-2002/view

Acesso em: 11 mai. 2018.

BAPTISTA. Adriana Mathias; OLIVEIRA, Jaime César de Moura. O Brasil em Fóruns Internacionais sobre Meio Ambiente e os Reflexos da Rio 92 na Legislação Brasileira. Revista Paranaense de Desenvolvimento, Curitiba, n. 102, p. 5-27, jan./jun. 2002. Disponível em: https://dialnet.unirioja.es/servlet/articulo?codigo=4813386 Acesso em: 30 jan. 2021.

BRASIL. Decreto s/n de 3 novembro de 1997. Homologa a demarcação administrativa da Terra Indígena Xambioá, localizada no Município de Araguaína, Estado do Tocantins. Disponível em: http://www.planalto.gov.br/ccivil_03/leis/19985.htm Acesso em: 14 abr. 2018.

BRASIL. Decreto s/n de 3 novembro de 1997. Homologa a demarcação administrativa da Terra Indígena Apinayé, localizada nos Municípios de Itaguatins, Maurilândia e Tocantinópolis, Estado do Tocantins. Disponível em: http://www2.camara.leg.br/legin/fed/decret sn/1997/decreto-46573-3-novembro-1997591232-publicacaooriginal-116333-pe.html Acesso em: 11 mai. 2018.

BRASIL. Empresa Brasileira de Pesquisa Agropecuária. Sobre o Matopiba. Disponível em: https://www.embrapa.br/tema-matopiba/sobre-o-tema Acesso em: 4 de junho de 2021.

BRASIL. Fundação Nacional do Índio. Modalidades de Terras Indígenas. Disponível em: http://www.funai.gov.br/index.php/indios-no-brasil/terras-indigenas Acesso em: 11 mai. 2018.

BRASIL. Instituto Brasileiro de Geografia e Estatística. Geociências. Disponível em: https://downloads.ibge.gov.br/downloads geociencias.htm Acesso em: 12 mai. 2018.

BRASIL. IBGE. Mapa de Biomas e de Vegetação. Disponível em: https://ww2.ibge.gov.br/home/presidencia/noticias/21052004biomashtml.shtm Acesso em: 12 de mai. 2018.

BRASIL. Instituto de Pesquisa Econômica Aplicada. O que é? Amazônia Legal. Disponível em: $\quad$ https://www.ipea.gov.br/desafios/index.php?option=com_content\&id=2154: catid=28 Acesso em: 5 de junho de 2020

BRASIL. Lei Federal no 9.985 de 18 de julho de 2000. Regulamenta o art. 225, § 1o , incisos I, II, III e VII da Constituição Federal, institui o Sistema Nacional de Unidades de Conservação 
da Natureza e dá outras providências. Disponível em: http://www.planalto.gov.br/ccivil 03/leis/19985.htm Acesso em: 14 abr. 2018.

BRASIL. Ministério do Meio Ambiente. Amazônia. Disponível em: http://www.mma.gov.br/biomas/amaz\%C3\%B4nia Acesso em: 12 mai. 2018.

BRASIL. Ministério do Meio Ambiente. O Bioma Cerrado. Disponível em: http://www.mma.gov.br/biomas/cerrado Acesso em: 12 mai. 2018.

BRASIL. Ministério do Meio Ambiente. Unidades de Conservação. Disponível em: http://www.mma.gov.br/areas-protegidas/unidades-de-conservacao Acesso em: 14 abr. 2018.

CASTRO JR., et al. Gestão da biodiversidade e áreas protegidas. In: GUERRA, A. J. T.; COELHO, Maria C. N. Unidades de Conservação: abordagens e características geográficas. Rio de Janeiro: Bertrand Brasil, 2009.

CHIAVENATO, Júlio José. O Massacre da Natureza. (Coleção Polêmica) São Paulo: Moderna, 1989.

COELHO, Maria Célia Nunes; CUNHA, Luis Henrique; MONTEIRO, Maurílio de Abreu. Unidades de Conservação: Populações, Recursos e Territórios. Abordagens da ECO, O. O que é a Convenção sobre a Diversidade Biológica. 22 de Maio de 2014. Disponível em: http://www.oeco.org.br/dicionario-ambiental/28347-o-que-e-a-convencao-sobre-adiversidade-biologica/ Acesso em: 13 de mai. 2018.

GABElini, S. M. Manual Prático de Unidades de Conservação: Ministério Público do Estado de Goiás, ESMP, 2011, 79 p.

GUERRA, Antonio José Teixeira; COELHO, Maria Célia Nunes (Org). Unidades de Conservação: Abordagens e Características Geográficas. Rio de Janeiro: Bertrand Brasil, 2009.

LEITE, Francisco Tarciso. Metodologia Científica: métodos e técnicas de pesquisa (Monografias, Dissertações, Teses e Livros). Aparecida - SP: Ideias e Letras, 2008.

MARTINS, Rosilda Baron. Metodologia Científica: como tornar mais agradével a elaboração de trabalhos acadêmicos. Curitiba: Juará, 2005.

OLIVEIRA, Adriano Dias de. MARANDINO, Martha. A biodiversidade no saber sábio: investigando concepções de biodiversidade na literatura e entre pesquisadores. Revista de educação ciência e matemática. Disponível em: http://publicacoes.unigranrio.edu.br/index.php/recm/article/view/1587 Acesso em: 5 de junho de 2021.

OLIVEIRA, Leonardo Basso de. As Concepções de Biodiversidade: do professor-formador ao professor de Biologia em serviço. Dissertação de mestrado. Faculdade de Educação da Universidade de São Paulo, 2005. 
TOCANTINS. Gestão das Unidades de Conservação do Tocantins. Unidades de Conservação. Disponível em: http://gesto.to.gov.br/uc/ Acesso em: 14 abr. 2018.

TOCANTINS. Secretaria do Planejamento e da Modernização da Gestão Pública. Áreas de uso Legal Restrito e Potenciais à Conservação Ambiental. Julho de 2012. Disponível em: http://web.seplan.to.gov.br/Arquivos/download/20120906150226to areas uso legal restrito jul2012.pdf Acesso em: 13 abr. 2018. 